\title{
New Values of Teucrium species: in Vitro Study of Cytotoxic Activities of Secondary Metabolites
}

\author{
Milan S. STANKOVIĆ ${ }^{1 *}$, Tatjana Lj. MITROVIĆ ${ }^{2}$ Ivana Z. MATIĆ \\ Marina D. TOPUZOVIĆ ${ }^{1}$, Slaviša M. STAMENKOVIĆ ${ }^{2}$
}

\author{
${ }^{1}$ University of Kragujevac, Faculty of Science, Department of Biology and Ecology, \\ 12 RadojaDomanovica, Kragujevac,Serbia; mstankovic@kg.ac.rs(*correspondingauthor); marina@kg.ac.rs \\ ${ }^{2}$ University of Nis, Faculty of Sciences and Mathematics, Department of Biology and Ecology, \\ 33Višgradska,Nis, Serbia; tatjanamitrovic3@gmail.com,sslavisa@pmf.ni.ac.rs \\ 3Institute of Oncology and Radiology of Serbia, 14 Pasterova, Belgrade, Serbia; ivanamatic@sbb.rs
}

\begin{abstract}
The cytotoxicity of seven Teucrium species, a long time ago used as a food spices, for beverages and teas preparing, as well as therapeutics for digestive and respiratory diseases, were examined against human cervix adenocarcinoma HeLa, human melanoma Fem-x, human chronic myelogenous leukemia K562 and human breast adenocarcinoma MDA-MB-361 cells. MTT assay was used for determination of target cell survival. The most prominent cytotoxic effect was observed against K562 cells, especially by T. scordioides, T. montanum and T. botrys. All Teucrium extracts showed good cytotoxic activity on HeLa cells, but very low cytotoxic effect on MDA-MB-361 cells. In addition, the cytotoxic activities of T. scordioides and T. montanum extract were tested on healthy resting and phytohaemagglutinin-stimulated peripheral blood mononuclear cells (PHAstimulated PBMC). T. scordioides and T. montanum extracts at concentration of $200 \mu \mathrm{g} / \mathrm{ml}$ reduced the resting PBMC and PHA-stimulated PBMC survival up to $10 \%$ and $20 \%$, while the reduction of K562 cell survival at the same concentration of extracts was $94 \%$ and $97 \%$, respectively. These results point to selectivity in their antitumor actions. Teucrium species can be regarded as promising candidates for natural plant sources of effective biological compounds as a supplements in the food industry, as well as for therapeutic use.
\end{abstract}

Keywords: anticancer properties, germanders of Serbian flora, malignant cell lines, MTT test

\section{Introduction}

Cancer continues to be a leading cause of death worldwide due to a limited success of available treatments for metastatic cancers (Jemal, 2012). There were an estimated 3.45 million new cases of cancer (excluding non-melanoma skin cancer) and 1.75 million deaths from cancer in Europe in 2012 (Ferlay et al., 2013). These facts inspired an increasing interest in plants as source of novel therapeutic agents. Only 1-10\% plant species out of the 250,000-500,000 species estimated on this planet, have been studied chemically and pharmacologically (Verpoorte, 2000).

The genus Teucrium L. (Lamiaceae) includes over 300 species commonly known as germanders and widespread all over the continents (Amirghofran et al., 2010). Some of these species are endemic to the Mediterran and Middle East area (Kästner, 1989). Nine species of Teucrium are native in central and west Balkan. They are mostly perennial herbs, shrubs or subshrubs, while $T$. botrys is a herbaceous annual herb. The Teucrium-based formulations have been used since ancient times as remedial measures against various human ailments. Traditional medicinal use of $T$. polium for treatment of abdominal pain, indigestion, common cold, diabetes and urogenital diseases dates back over two thousand years (Bahramikia and Yazdanparast, 2012; Rajabalian, 2008; Said et al., 2002). T. chamaedrys, T. montanum and $T$. scordium are the most popular traditional remedies in the Balkan area (Kundaković et al., 2011). They are used as tonic, bitter, antianemic, cholagogue, antimotility, febrifuge and vulnerary agents (Jarić et al., 2007; Kundaković et al., 2011; Redžić, 2007).

The Teucrium species are considered as a potential source of diterpenoids, flavonoids, phenols, iridoids, sterols and terpenoids (Bahramikia and Yazdanparast, 2012; Eskandary et al., 2007; Rajabalian, 2008). Diterpenoids and flavonoids are usually responsible for anti-cancer properties of Teucrium extracts. For instance, anti-cancer chemosensitizer effects of diterpenoids and methanolic extracts of $T$. polium and vincristine, vinblastine and doxorubicin against Skmel-3 (melanoma), Saos-2 (osteosarcoma), SW480 (colon carcinoma), MCF-7 (breast 
42

carcinoma), KB (oral cavity epidermal cell line), EL (bladder carcinoma) and A431 (epidermoid carcinoma) cells are demonstrated (Rajabalian, 2008). Also, flavonoids are considered as strong inducers of apoptosis (Haidara, 2011).

The anticancer properties of Teucrium extracts and compounds are tested on various types of human cancer cell lines, such as bladder carcinoma (EL, Fen), breast adenocarcinoma (MCF-7, estrogen-dependant MDA-MB-361, estrogen-nondependant MDA-MB-453), Burkitt's lymphoma (Raji), cervix epitheloid carcinoma (HeLa), chronic myelogenous leukemia (K562), colon carcinoma (CACO-2, HCT-116, LoVo, SW480), epidermoid carcinoma (A431), glioblastoma multiforme (REYF-1), hepatoblastoma (HepG2), larynx carcinoma (Hep-2), lung carcinoma (COR-123), non-small cell lung cancer (H322, A549), melanoma (C32, Skmel-3), osteosarcoma (Saos-2), prostate carcinoma (DU145, PC3), T cell leukemia (Jurkat), etc. (Abu-Dahab and Affifi, 2007; Amirghofran et al., 2010; Eskandary et al., 2007; Haidara, 2011; Kandouz et al., 2010; Kundaković et al., 2011; Menichini et al., 2009; Pacifico et al., 2012; Rajabalian, 2008; Sghaier et al., 2012; Stanković et al., 2011; Talib and Mahasneh, 2010; Yin et al., 2009).

Previously, chemical content of methanolic extracts of seven Teucrium species - T. scordioides, T. scordium, T. chamaedrys, $T$. polium, T. montanum, T. arduini and T. botrys was compared with theirs antiproliferative, proapoptotic and antioxidant properties (Stanković et al., 2011). The highest content of phenolic compounds and the best cytotoxicity activity on human colon carcinoma cells HCT-116 were observed with methanolic extract of T. chamaedrys and T. arduini (Stanković $e t$ al., 2011). Kundaković and colleagues (2011) explored cytoxicity and antimicrobial activity of cyclohexane, dichlormethane and methanolic extracts of $T$. scordioides. They observed high cytotoxicity of cyclohexane and dichlormethane and lack of cytotoxicity of the methanolic extracts of $T$. scordioides on breast cancer cell lines (MDA-MB-361 and MDA-MB-453).

The aim of this study was further evaluation of anticancer potential of methanolic extracts of seven Teucrium species - $T$. scordioides, T. scordium, T. chamaedrys, T. polium, T. montanum, T. arduini and T. botrys against novel set of cancer cells (HeLa, Fem-x, K562, MDA-MB-361). Also, the extracts which showed the most notable cytotoxicity (T. scordioides and T. montanum) were examined on normal human immunocompetent peripheral blood mononuclear cells (PBMC) - on resting and stimulated to proliferate by the mitogen phytohemagglutinin (PHA).

\section{Materials and methods}

\section{Chemicals}

Methanol, potassium hydroxide $(\mathrm{KOH})$ and sodium nitrite $\left(\mathrm{NaNO}_{3}\right)$ were purchased from - Zorka pharma, Serbia. $N-(1-$ naphthyl)ethylenediamine were purchased from Fluka Chemie AG, Buchs, Switzerland. Fetal bovine serum (FBS) and trypsinEDTA were from PAA (The cell culture company), Austria. Dimethyl sulfoxide (DMSO), nitro blue tetrazolium (NBT), ethidium bromide and 3-[4,5-dimethylthiazol-2-yl]-2,5diphenyltetrazolium bromide (MTT) were obtained from SERVA, Germany and sulfanilic acid from MP Hemija, Serbia.

\section{Plant material}

From June to September 2009 aerial flowering parts of Teucrium species were collected from natural populations in the regions of Serbia and Montenegro. The voucher specimens of T. scordioides, T. scordium L., T. chamaedrys L., T. polium L., T. montanum L., T. arduini L. and T. botrys L., were confirmed and deposited in Herbarium at the Department of Biology and Ecology, Faculty of Science, University of Kragujevac. The collected plant material was air-dried in darkness at ambient temperature $\left(20^{\circ} \mathrm{C}\right)$. The dried plant material was cut up and stored in tightly sealed dark containers until needed.

\section{Preparation of plant extracts}

Prepared plant material $(10 \mathrm{~g})$ was transferred to darkcolored flasks and was soaked in $200 \mathrm{ml}$ of methanol and stored at room temperature. After $24 \mathrm{~h}$, the infusions were filtered through Whatman No. 1 filter paper and residue was re-extracted with equal volume of solvents. After $48 \mathrm{~h}$, the process was repeated. Combined supernatants were evaporated to dryness under vacuum at $40^{\circ} \mathrm{C}$ a using Rotary evaporator. The obtained extracts were kept in sterile sample tubes and stored in a refrigerator at $4{ }^{\circ} \mathrm{C}$.

\section{Cell culture}

Human cervix adenocarcinoma HeLa, human melanoma Fem-x and human breast adenocarcinoma MDA-MB-361 cells were cultured as monolayers. Human chronic myelogenous leukemia K562 cells were grown in a suspension in nutrient medium. Cancer cell lines were obtained from the American Type Culture Collection (Manassas, VA, USA). The complete nutrient medium was RPMI 1640 supplemented with $3 \mathrm{mM}$ L-glutamine, $100 \mu \mathrm{g} / \mathrm{ml}$ streptomycin, $100 \mathrm{IU} / \mathrm{ml}$ penicillin, $10 \%$ heat-inactivated $\left(56^{\circ} \mathrm{C}\right)$ fetal bovine serum and $25 \mathrm{mM}$ Hepes adjusted to $\mathrm{pH}$ 7.2 with a bicarbonate solution. The cells were grown at 37 ${ }^{\circ} \mathrm{C}$ in an atmosphere of $5 \% \mathrm{CO}_{2}$ and humidified air. RPMI 1640, L-glutamine and Hepes were obtained from PAA (Pasching, Austria).

\section{Preparation of peripheral blood mononuclear cells}

Peripheral blood mononuclear cells (PBMC) were separated from whole heparinized blood of two healthy volunteers by Lymphoprep (Oslo, Norway) gradient centrifugation. Interface cells were washed three times with Haemaccel (aqueous solution supplemented with $145 \mathrm{mM}$ $\mathrm{Na}^{+}, 5.1 \mathrm{mM} \mathrm{K}^{+}, 6.2 \mathrm{mM} \mathrm{Ca}^{+}, 145 \mathrm{mM} \mathrm{Cl}$ and $35 \mathrm{~g} /$ lgelatin polymers, $\mathrm{pH} 7.4$ ), counted and resuspended in nutrient medium.

\section{Treatment of cancer cell lines}

HeLa (2,000 cells per well), Fem-x (5,000 cells per well), MDA-MB-361 (10,000 cells per well) were seeded into 96well microtiter plates and $20 \mathrm{~h}$ later, after cell adherence, five different concentrations of the plant extracts were added to the wells. Nutrient medium was only added to the cells in the control wells. K562 cells (5,000 cells per well) were seeded $2 \mathrm{~h}$ before addition of the extracts. Stock solutions of the extracts were made in dimethyl sulfoxide (DMSO) at a concentration of $20 \mathrm{mg} / \mathrm{ml}$. They were diluted with complete nutrient medium and applied to cells at five different final 
concentrations that ranged from $12.5 \mu \mathrm{g} / \mathrm{ml}$ to $200 \mu \mathrm{g} / \mathrm{ml}$. All experiments were done in triplicate. Cisplatin was used as a positive control.

\section{Treatment of PBMC}

PBMC (150,000 cells per well) were seeded into nutrient medium or in nutrient medium enriched with PHA (5 $\mu \mathrm{g} / \mathrm{ml}$ ) in 96-well microtiter plates. After $2 \mathrm{~h}$, five different concentrations of the plant extracts were added to the wells, in triplicate, except to the control wells where a nutrient medium only was added to the cells. The final concentrations of the tested extracts ranged from $12.5 \mu \mathrm{g} / \mathrm{ml}$ to $200 \mu \mathrm{g} / \mathrm{ml}$. PHA was obtained from INEP (Belgrade, Serbia). Cisplatin was used as a positive control.

\section{Determination of target cell survival}

Cell survival was determined by the MTT test according to the method of Mosmann (1983) modified by Ohno and Abe (1991). Briefly, after the treatment with plant extracts for $72 \mathrm{~h}, 10 \mu \mathrm{l}$ of MTT solution (3-(4,5-dimethylthiazol-2yl)-2,5-dyphenyl tetrazolium bromide) was added to each well. Samples were incubated for a further $4 \mathrm{~h}$, followed by the addition of $100 \mu \mathrm{l}$ of $10 \%$ SDS. Absorbance at $570 \mathrm{~nm}$ was measured the next day.

To quantify cell survival (S\%), the absorbance of a sample with cells grown in the presence of different concentrations of the investigated agents was divided by the absorbance of the control cells grown only in the nutrient medium, and multiplied by 100 . It is implied that the absorbance of the blank was always subtracted from the absorbance of the corresponding sample with target cells. The $\mathrm{IC}_{50}$ was defined as the concentration of the agent that inhibited cell survival by $50 \%$, compared to the vehicle-treated control.

\section{Results and discussions}

Cytotoxic effects of methanolic extracts of seven different plant species from the genus Teucrium were examined on the selected malignant cell lines: human cervix adenocarcinoma
HeLa, human melanoma Fem-x, human chronic myelogenous leukemia K562 and human breast adenocarcinoma MDA-MB361 cells. The investigated Teucrium extracts exhibited selective dose-dependent cytotoxic activities against target malignant cells (Table 1 and Fig. 1). Each of the Teucrium extracts exerted the most pronounced cytotoxic action against myelogenous leukemia K562 cells. The highest cytotoxic activity against K562 cells was demonstrated for methanolic extract of T. scordioides known previously for the highest content of phenolic compounds and the best cytotoxicity activity on human colon carcinoma cells HCT-116 (Stanković et al., 2011). Besides, high performance liquid chromatography (HPLC) analysis of this extract revealed presence of flavonoid aglycones (luteolin, apigenin and diosmetin) and their glycosides (luteolin-7-Oglucoside, luteolin-7-O-rutinoside and diosmetin-7-O-glucoside) (Kundaković et al., 2011). Extracts of T. montanum and T. botrys showed similar intensities of notable cytotoxic action on K562 cells as the one above reported for the extract of $T$. scordioides. All seven Teucrium extracts demonstrated pronounced cytotoxic effects against cervix adenocarcinoma HeLa cells. Additionally, these plant extracts exhibited very low cytotoxic effects against melanoma Fem- $\mathrm{x}$ and breast adenocarcinoma MDA-MB-361 cells as noticed previously (Kundaković et al., 2011). The intensities of cytotoxic activity of seven methanolic Teucrium extracts against particular malignant cell line did not differ significantly (Table 1). Photomicrographs of HeLa and K562 cells obtained after the treatment with plant extracts for $72 \mathrm{~h}$ applied at a concentration of $200 \mu \mathrm{g} / \mathrm{ml}$ demonstrate that Teucrium plant extracts induced significant decrease in the number of survived cells in comparison to cells in the control sample (Fig. 2).

To evaluate the sensitivity of the healthy immunocompetent cells, involved in the antitumor immune response, the cytotoxic activities of $T$. scordioides extract and T. montanum extract were tested against resting and PHA-stimulated PBMC. These data are presented in Table 2 and Fig. 3. At concentrations up to 200 $\mu \mathrm{g} / \mathrm{ml}$ these plant extracts did not exert notable cytotoxic action against unstimulated PBMC. T. scordioides extract and T. montanum extract at a concentration of $200 \mu \mathrm{g} / \mathrm{ml}$ reduced the

Table 1. Concentrations of Teucrium extracts which induced $50 \%$ decrease in cancer cell survival, determined by the MTT test

\begin{tabular}{|c|c|c|c|c|}
\hline & $\mathrm{HeLa}$ & Fem-x & K562 & MDA-MB-361 \\
\hline T. scordioides $\mathrm{IC}_{50}[\mu \mathrm{g} / \mathrm{ml}]$ & $139.96 \pm 12.11$ & $>200$ & $96.63 \pm 28.61$ & $196.5^{*}$ \\
\hline T. scordium $\mathrm{IC}_{50}[\mu \mathrm{g} / \mathrm{ml}]$ & $144.82 \pm 10.24$ & $\approx 200$ & $102.48 \pm 22.04$ & $\approx 200$ \\
\hline T. chamaedrys $\mathrm{IC}_{50}[\mu \mathrm{g} / \mathrm{ml}]$ & $146.47 \pm 22.04$ & $190.16 \pm 13.92$ & $102.71 \pm 24.46$ & $188.28 \pm 2.94$ \\
\hline T.polium $\mathrm{IC}_{50}[\mu \mathrm{g} / \mathrm{ml}]$ & $148.02 \pm 4.99$ & $199.79 \pm 0.30$ & $116.75 \pm 24.40$ & $\approx 200$ \\
\hline T. montanum $\mathrm{IC}_{50}[\mu \mathrm{g} / \mathrm{ml}]$ & $152.34 \pm 15.88$ & $196.44 \pm 5.03$ & $99.15 \pm 11.92$ & $>200$ \\
\hline T. arduini $\mathrm{IC}_{50}[\mu \mathrm{g} / \mathrm{ml}]$ & $137.51 \pm 2.22$ & $>200$ & $113.38 \pm 14.94$ & $\approx 200$ \\
\hline T. botrys $\mathrm{IC}_{50}[\mu \mathrm{g} / \mathrm{ml}]$ & $164.23 \pm 18.92$ & $\approx 200$ & $98.78 \pm 7.84$ & $\approx 200$ \\
\hline Cisplatin $\mathrm{IC}_{50}[\mu \mathrm{M}]$ & $5.39 \pm 1.21$ & $6.16 \pm 0.31$ & $5.34 \pm 1.60$ & $37.42 \pm 7.32$ \\
\hline
\end{tabular}

Time of continuous agent's action was $72 \mathrm{~h}$

$\mathrm{IC}_{50}$ data are mean \pm SD values of three independent experiments

Table 2. Concentrations of Teucrium scordioides and T. montanum extracts which induced $50 \%$ decrease in PBMC survival, determined by the MTT test

\begin{tabular}{lcc} 
& & \\
& PBMC & PBMC + PHA \\
\hline$T$. scordioides $\mathrm{IC}_{50}[\mu \mathrm{g} / \mathrm{ml}]$ & $>200$ & $>200$ \\
$T$. montanum $\mathrm{IC}_{50}[\mu \mathrm{g} / \mathrm{ml}]$ & $>200$ & $>200$ \\
Cisplatin $\mathrm{IC}_{50}[\mu \mathrm{M}]$ & $>66.67$ & $>66.67$ \\
\hline
\end{tabular}

Time of continuous agent's action was $72 \mathrm{~h}$

IC 50 data are mean \pm SD values of two independent experiments 
44

HeLa

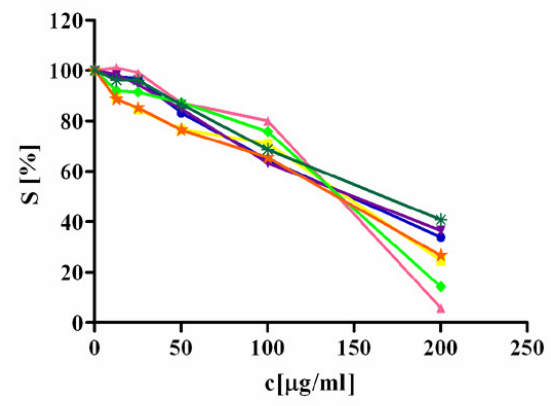

K562

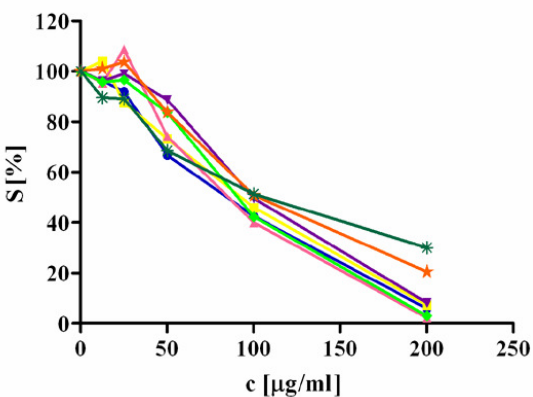

Fem-x

- T. scordioides

T. scordium

- T. chamaedrys

- T. polium

$\rightarrow$ T. montanum

* T. arduini

* T. botrys

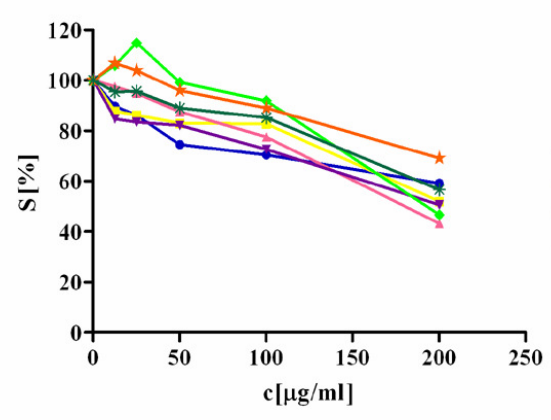

MDA-MB-361

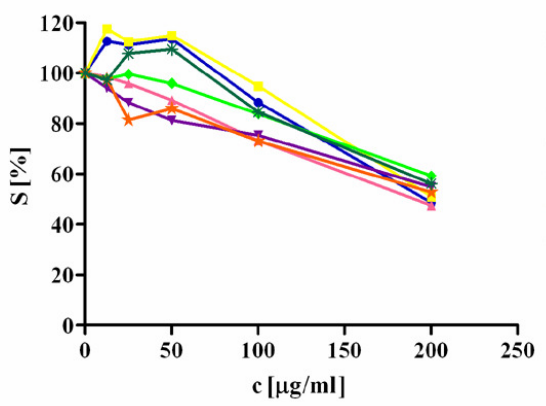

Fig. 1. Survival of HeLa, Fem-x, K562 and MDA-MB-361 cells grown for $72 \mathrm{~h}$ in the presence of increasing concentrations of Teucrium extracts determined by the MTT test. Representative graphs are shown

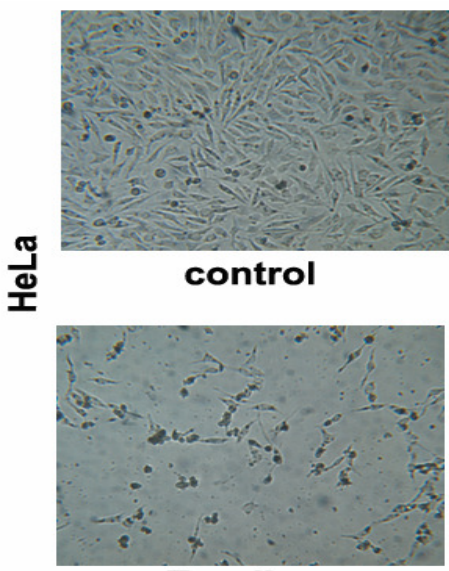

T. polium

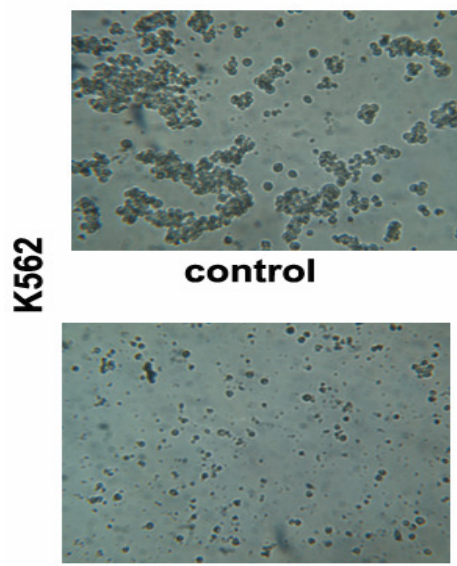

T. polium

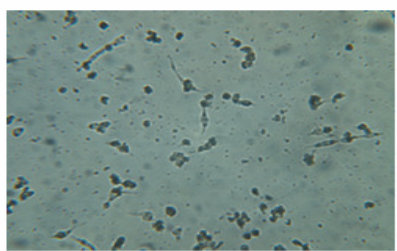

T. scordioides

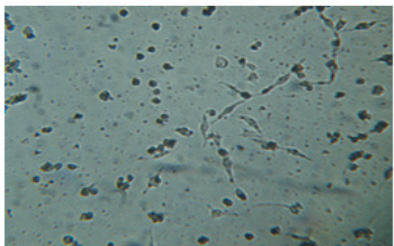

T. montanum

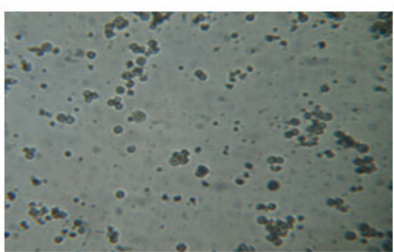

T. scordioides

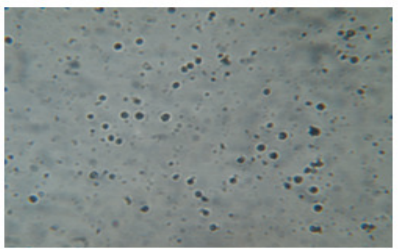

T. montanum

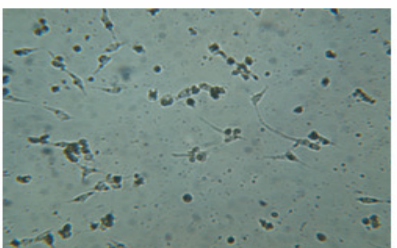

T. scordium

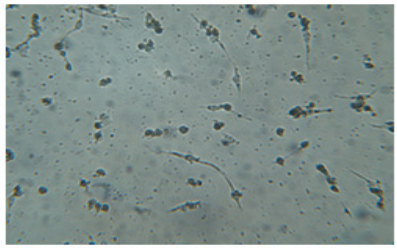

T. arduini

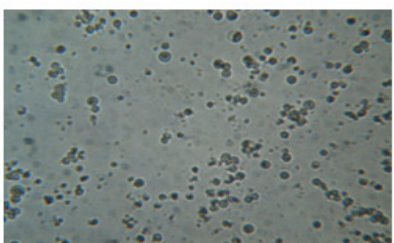

T. scordium

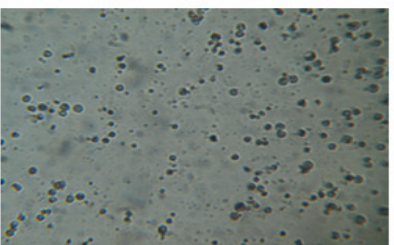

T. arduini

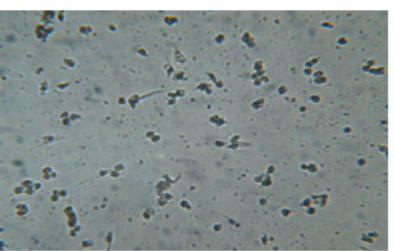

T. chamaedrys

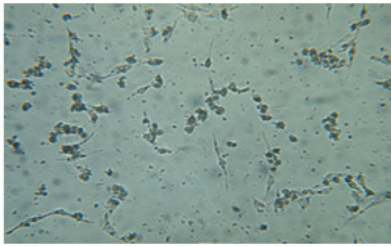

T. botrys

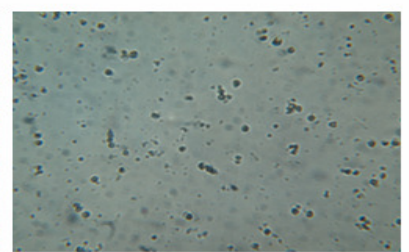

T. chamaedrys

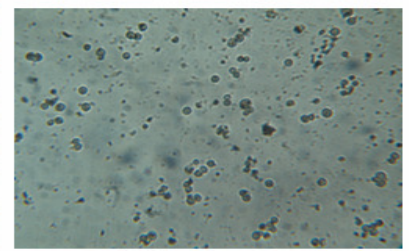

T. botrys

Fig. 2. Photomicrographs of HeLa and K562 cells obtained after $72 \mathrm{~h}$ treatment with Teucrium extracts 
PBMC

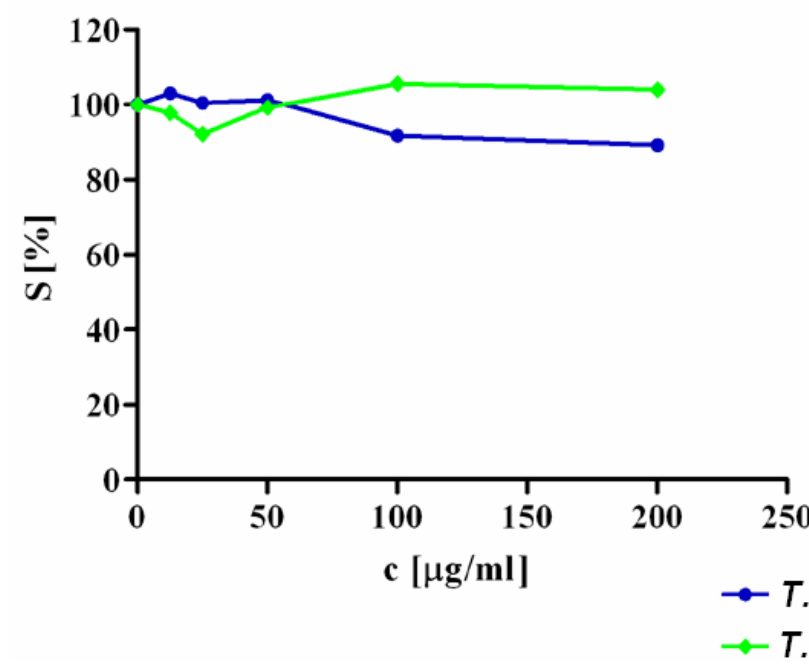

PBMC+PHA

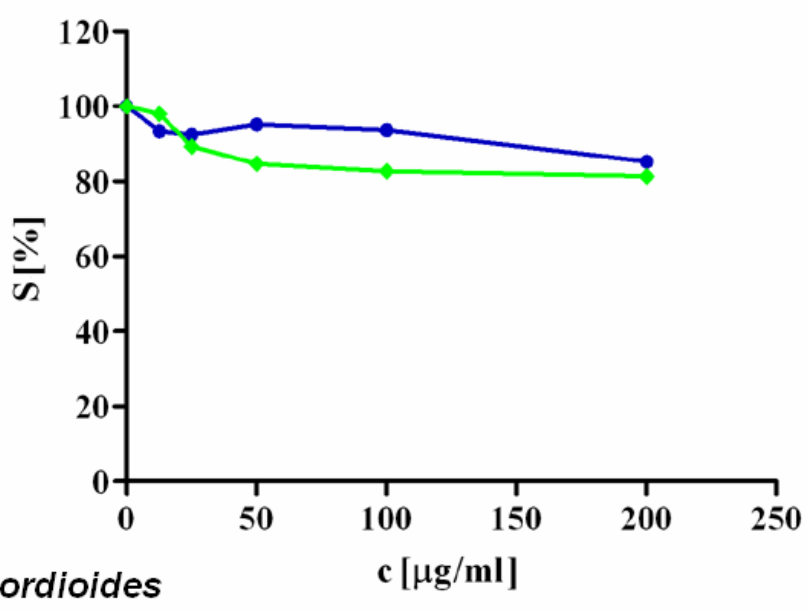

Fig. 3. Survival of resting PBMC and PHA-stimulated PBMC grown for $72 \mathrm{~h}$ in the presence of increasing concentrations of Teucrium scordioides and T. montanum extracts, determined by the MTT test. Representative graphs are shown

resting PBMC survival up to $10 \%$. On the other hand, tested extracts at the concentration of $200 \mu \mathrm{g} / \mathrm{ml}$ induced decrease in the PHA-stimulated PBMC survival up to $20 \%$. It is noteworthy that when applied at the same concentrations these two extracts exhibited pronounced cytotoxic actions against malignant cell lines, especially against K562 cells (by reducing the K562 cell survival for $94 \%$ and $97 \%$ respectively), pointing to selectivity in their antitumor action. In view of obtained results, other Teucrium plant extracts whose effects against PBMC were not tested, are expected to display the same selectivity in the cytotoxic action against malignant cells in comparison to healthy immunocompetent cells.

Generally, the cell-type specific sensitivity to the tested extracts are considered to reflect the difference in the presence of various classes of compounds in the extracts (such as polyphenols and flavonoids) and their modes of action. Phenolic compounds as the most abundant polar fraction of methanolic extract and the most responsible for its antioxidative activities modulate carcinogenesis through two main mechanisms: modification of redox status and interference of basic cellular functions (cell cycle, apoptosis, inflammation, angiogenesis, invasion and metastasis) (Amiri 2010; Kampa, 2007; Stanković et al., 2011). On the other hand, flavonoid compounds in Teucrium extracts are believed to be apoptosis-inducers through p 53 and other regulators of apoptosis (Haidara et al., 2011; Lin $e t$ al., 2008). Also, flavonoids are able to influence a variety of cell functions by modulating cell signaling and inhibiting cancer cell proliferation and migration. For instance, flavonoids as major bioactive compounds of $T$. polium extract showed inhibition of human prostate cancer cells (DU145 and PC3) proliferation, decreasement of the cancer cell invasion and metastasis, induction of differentiation to an epithelial phenotype "mesenchymal-epithelial transition" and re-localization of the expression patterns of E-cadherin and catenins (Al Bahtiti, 2012; Haidara et al., 2011; Kandouz et al., 2010). T. polium extract inhibited the phosphorylation of beta-catenin, via Src dephosphorylation, and consequently converted its role from a transcriptional regulator to a cell-cell adhesion molecule
(Kandouz et al., 2010). Kandouz et al. (2010) concluded that $T$. polium extract inhibited signaling pathways involved in regulating the E-cadherin/catenin complex and possibly other cell-cell adhesion genes via beta-catenin alteration.

\section{Conclusions}

Seven Teucrium species out of nine widespread in the Balkan (T. scordioides, T. scordium, T. chamaedrys, T. polium, T. montanum, $T$. arduini and $T$. botrys) were evaluated against four different malignant cell lines (HeLa, Fem-x, K562 and MDA-MB-361). Examined Teucrium extracts showed selective dose-dependent cytotoxic activities against target malignant cells. The strongest cytotoxic effects of the tested extracts were observed against leukemia K562 cells, especially of the $T$. scordioides, T. montanum and T. botrys methanolic extracts. It should be noted that $T$. scordioides and T. montanum extracts exerted notable selectivity in their cytotoxic actions against $\mathrm{K} 562$ cells in comparison to normal human immunocompetent PBMC. These species should be studied thoroughly for effective anti-cancer components. The Teucrium species represent potent natural source of future anti-cancer drugs or chemosensitizers of available cytostatics.

\section{Acknowledgements}

This work was supported by the Ministry of Science and Education of the Republic Serbia (grant numbers: III41010, III41018 and OI 171025).

\section{References}

Abu-Dahab R, Afifi F (2007). Antiproliferative activity of selected medicinal plants of Jordan against a breast adenocarcinoma cell line (MCF7). Sci Pharm 75:121-136. 
46

Al Bahtiti NH (2012). "Teucrium polium" extract Jordanian Ja’adeh. Asian J Agr Sci 4:379-382.

Amirghofran Z, Zand F, Javidnia K, Miri R (2010). The citotoxic activity of various herbals against different tumor cells: an in vitro study. Iran Red Crescent Med J 12:260-265.

Amiri H (2010). Antioxidant activity of the essential oil and methanolic extract of Teucrium orientale L. subsp. taylori (Boiss.) Rech. f. Iran J Pharm Res 9:417-423.

Bahramikia S, Yazdanparast R (2012). Phytochemistry and medicinal properties of Teucrium polium L. (Lamiaceae). Phytother Res 26:1581-1593.

Eskandry H, Rajabalian S, Yazdi T, Eskandari M, Fatehi K, Ganjooei NA (2007). Evaluation of cytotoxic effects of Teucrium polium on a new glioblastoma cell line (REYF-1) using MTT and soft agar clonogenic assays. Int J Pharmacol 3:435-437.

Ferlay J, Steliarova-Foucher E, Lortet-Tieulent J, Rosso S, Coebergh JWW, Comber H, Forman D, Bray F (2013). Cancer incidence and mortality patterns in Europe: estimates for 40 countries in 2012. Eur J Cancer 49:1374-1403.

Haidara K, Alachkar A, Al Moustafa A-E (2011). Teucrium polium plant extract provokes significant cell death in human lung cancer cells. Health 3:366-369.

Jarić S, Popvić Z, Mačukanović-Jocić M, Đurđević L, Mijatović M, Karadžić B, Mitrović M, Pavlović P (2007). An ethnobotanical study on the usage of wild medicinal herbs from Kopaonik Mountain (Central Serbia). J Ethnopharmacol 111:160-175.

Jemal A (2012). Global burden of cancer: opportunities for prevention. The Lancet 380:1797-1799.

Kampa M, Nifli AP, Notas G, Castanas E (2007). Polyphenols and cancer cell growth. Rev Physiol Biochem Pharmacol 159:79-113.

Kandouz M, Alachkar A, Zhang L, Dekhil H, Chenna F, Yasmeen A, Al Moustafa AE (2010). Teucrium polium plant extract inhibit cell invasion and motility of human prostate cancer cells via restoration of the E-cadherin/catenin complex. J Ethnopharmacol 129:410-415.

Kästner A (1989). Übersicht zur systematischen gliederung der gattung Teucrium L. Biocosme Mésogéen 6:63-78.

Kundaković T, Milenković M, Topić A, Stanojković T, Juranić Z, Lakušić B (2011). Cytotoxicity and antimicrobial activities of Teucrium scordium L. (Lamiaceae) extracts. Afr J Microbiol Res 5:2692-2696.

Lin Y, Shi R, Wang X, Shen HM (2008). Luteolin, a flavonoid with potential for cancer prevention and therapy. Curr Cancer Drug Targets 8:634-646.
Menichini F, Conforti F, Rigano D, Fermisano C, Piozzi F, Senatore F (2009). Phytochemical composition, antiinflamatory and antitumour activities of four Teucrium essential oils from Greece. Food Chem 115:679-686.

Mosmann T (1983). Rapid colorimetric assay for cellular growth and survival: application to proliferation and cytotoxicity assays. J Immunol Methods 65:55-63.

Ohno M, Abe T (1991). Rapid colorimetric assay for the quantification of leukemia inhibitory factor (LIF) and interleukin-6 (IL-6).J Immunol Methods 145:199-203.

Pacifico S, D’Abrosca B, Scognamiglio M, D’Angelo G, Gallicchio M, Galasso S, Monaco P, Fiorentino A (2012). NMR-based metabolic profiling and in vitro antioxidant and hepatotoxic assessment of partially purified fractions from Golden germander (Teucrium scordium L.) methanolic extracts. Food Chem 135:1957-1967.

Rajabalian S (2008). Methanolic extract of Teucrium polium L. potentiates the cytotoxic and apoptotic effects of anticancer drugs of vincristine, vinblastine and doxorubicin against a panel of cancerous cell lines. Exp Oncol 30:133-138.

Redžić SS (2007). The ecological aspect of ethnobotany and ethnopharmacology of population in Bosnia nad Herzegovina. Col Antropol 31:869-890.

Said O, Khalil K, Fulder S, Azaizeh H (2002). Ethnopharmacological survey of medicinal herbs in Israel, the Golan Heights and the West Bank region. J Ethnopharmacol 83:251-265.

Sghaier MB, Skandrani I, Khochtali MS, Bhouri W, Gheidera K, Chekir-Gheidera L (2012). In vitro evaluation of antioxidant, cytotoxic and apoptotic activities of different extracts from the leaves of Teucrium ramosissimum (Lamiaceae). J Med Plants Res 6:3818-3825.

Stanković MS, Ćurčić MG, Žižić JB, Topuzović MD, Solujić SR, Marković SD (2011). Teucrium plant species as natural sources of novel anticancer compounds: antiproliferative, proapoptotic and antioxidant properties. Int J Mol Sci 12:4190-4205.

Talib WH, Mahasneh AM (2010). Antiproliferative activity of plant extracts used against cancer in traditional medicine. Sci Pharm 78:33-45.

Verpoorte R (2000). Pharmacognosy in the new millennium: leadfinding and biotechnology. J. Pharm Pharmacol 52:253262.

Yin G, Zeng H, He M, Wang M (2009). Extraction of Teucrium manghuaense and evaluation of the bioactivity of its extract. Int J Mol Sci 10:4330-4341. 